\title{
STRATEGI PEMANFAATAN PROGRAM BRIGADE ALAT DAN MESIN PERTANIAN (BAST)
}

\section{Strategy for Utilizing the Agricultural Equipment and Machine Brigade Program (BAST)}

\author{
Nila Riska, Didi Rukmana, Rusli M. Rukka. \\ Program Studi Agribisnis, Departemen Sosial Ekonomi Pertanian, Fakultas Pertanian, \\ Universitas Hasanuddin, Makassar \\ *Kontak penulis: riskanila05@gmail.com
}

\begin{abstract}
The tool and agricultural machinery brigade (BAST), a movement formed between elements of the government, regional government, the ranks of the TNI, farmer institutions and the driving force of agricultural modernization is expected to optimize Alsintan's distribution to farmers. The agricultural machinery and machinery brigade (BAST) program provides another alternative to the lack of use of tools available at the farmer. This research was conducted in Mukti Sari Village, North Luwu Regency. All data and information obtained using the APPAS method (Development Planning Analysis). The results of this analysis indicate that the main problem is that the needs of Alsintan users have not been fulfilled. The main problem is due to a short loan period, there has been no effort in the approach to BAST, and the tool operator is out of focus. This main problem causes the investment of Gapoktan in procuring its own equipment to be low. To solve this problem, we need to fulfill the main objectives, namely the needs of Alsintan users by farmers. This main objective is achieved if the loan lending period increases, there are efforts in the approach to BAST, and the workforce of the operator focuses on work. The main target is to raise Gapoktan investment in the procurement of its own high equipment. The actions needed to achieve the main goal, namely to submit an application for the addition of a loan period, appoint workforce to coordinate with BAST and supervise operator performance.
\end{abstract}

Keywords: Planning, Development, Case.

\begin{abstract}
Abstrak
Brigade alat dan mesin pertanian (BAST) yaitu gerakan yang dibentuk antara unsur pemerintah, pemerintah daerah, jajaran TNI, kelembagaan petani serta generasi penggerak modernisasi pertanian diharapkan dapat mengoptimalisasi penyaluran Alsintan ke petani. Program brigade alat dan mesin pertanian (BAST) memberikan alternatif lain dari kurangnya pemanfaatan alat yang tersedia di petani. Penelitian ini dilakukan di Desa Mukti Sari, Kabupaten Luwu Utara. Keseluruhan data dan informasi yang diperoleh dengan menggunakan metode APPAS (Analisis Perencanaan Pengembangan). Hasil analisis ini menunjukkan bahwa masalah utama yaitu kebutuhan pengguna alsintan belum terpenuhi. Masalah utama ini disebabkan karena masa pinjam alat yang singkat, belum ada upaya dalam pendekatan pada BAST, dan tenaga operator alat tidak fokus. Masalah utama ini menyebabkan investasi Gapoktan dalam pengadaan alat sendiri rendah. Untuk menyelesaikan permasalahan ini, diperlukan sasaran utama yaitu kebutuhan pengguna alsintan oleh petani terpenuhi. Sasaran utama ini tercapai apabila masa pinjam alat bertambah, adanya upaya dalam pendekatan pada BAST, dan tenaga kerja operator fokus dalam bekerja. Sasaran utama menyebakan investasi Gapoktan dalam pengadaan alat sendiri tinggi. Tindakan yang diperlukan untuk mencapai sasaran utama yaitu mengajukan permohonan penambahan masa pinjam alat, menunjuk tenaga kerja untuk berkoordinasi dengan BAST dan melakukan pengawasan terhadap kinerja operator.
\end{abstract}


Kata Kunci: Perencanaan, Pengembangan, Kasus.

Sitasi: Riska, N., D. Rukmana, R. M. Rukka. 2020. Strategi Pemanfaatan Program Brigade Alat Dan Mesin Pertanian (Bast) , JSEP 16(1): 83 - 94.

\section{Pendahuluan}

Sektor pertanian hingga saat ini masih memiliki peranan yang sanggat penting di dalam suatu pembangunan nasional dan juga sebagai penopang perekonomian bangsa. Sehubungan dengan pembangunan pertanian di Indonesia tetap dianggap penting dari keseluruhan pembangunan ekonomi, hal ini dapat dilihat saat sektor pertanian memberikan kontribusi yang besar dibandingkan sektor-sektor yang lainnya terhadap pertumbuhan ekonomi Indonesia. Dengan adanya pembangunan pertanian disebutkan bahwa suatu pembangunan pertanian adalah dengan mewujudkan swasembada pangan dan meningkatkan produksi hasil pertanian untuk masa mendatang (Togatorop, 2017).

Usaha dari suatu proses pembangunan itu tidak lepas dari adanya informasi dan teknologi pertanian menjadi sangat penting, dengan harapan akan terjadi suatu perubahan prilaku maupun kemampuan petani, dalam menggunakan teknologi. Dengan memanfatkan teknologi diharapkan mampu untuk mempercepat proses budidaya dan pasca panen yang efektif dan efisien. Dimana teknologi pertanian itu sendiri dapat menggantikan tenaga manusia didalam usaha tani yang mampu meningkatkan produksi dari hasil usaha tani (Togatorop, 2017).

Dalam rangka mendukung pengembangan mekanisasi pertanian terpadu dengan penerapan teknologi yang tepat, Kementerian Pertanian berupaya untuk memberikan bantuan berupa paket alat dan mesin pertanian (Alsintan) kepada masyarakat yang dikelola melalui UPJA maupun Dinas Pertanian Provinsi/Kabupaten/Kota dan Jajaran TNI-AD di kabupaten khususnya Satuan Komando Kewilayahan (Korem/Kodim) yang dikelola dalam bentuk Brigade Alsintan (Kementrian Pertanian, 2017).

Di Kabupaten Luwu Utara merupakan salah satu sentra lumbung padi dimana sistem usahatani yang ada di Kabupaten Luwu Utara dari segi penggunaan teknologi dari tahun ketahun mengalami perkembangan, terutama dari penggunaan Alat dan Mesin Pertanian (Alsintan). Alat dan Mesin Pertanian (Alsintan) merupakan suatu teknologi yang mampu meminimalisir semua faktor-faktor produksi dalam melakukan usaha taninya, diantaranya adalah dari segi waktu, tenaga dan bertujuan mendapatkan produksi yang lebih baik disetiap pemanenan padi.

Brigade Alat dan Mesin Pertanian yaitu gerakan yang dibentuk antara unsur pemerintah, pemerintah daerah, jajaran TNI, kelembangaan petani serta generasi penggerak modernisasi pertanian diharpakan dapat mengoptimalisasi penyaluran alsintan kepetani (Kementrian Pertanian, 2017).

Dengan adanya bantuan Brigade Alat dan Mesin Pertanian (BAST) yang ada di Kabupaten Luwu Utara, kepada petani guna membantu para petani untuk bisa lebih meningkatkan produksi padinya. Dari tahun ketahun secara konsisten pemerintah selalu memberi dukungan berupa bantuan alat dan Mesin Pertanian (Alsintan) kepada petani. Tujuan yang dicapai adalah terwujudnya masyarakat yang berdaya, yang mampu dan masyarakat yang mandiri guna mewujudkan masyarakat petani yang sejahtera. Program Brigade Alat dan Mesin Pertanian (BAST) ini dari tahun ketahun semakin ditingkatkan seiring dengan era teknologi sekarang ini, maka hal ini akan sangat membantu petani di dalam melakukan usahataninya. Berdasarkan penjelasan tersebut maka peneliti melakukan suatu penelitian tentang "Strategi Pemanfaat Program Brigade Alat dan Mesin Pertanian (BAST) (Studi Kasus pada Yunit Gapoktan Rafi Musri, di Desa Muktisari Kecamatan Bone-Bone di Kabupaten Luwu Utara, Provinsi Sulawesi Selatan). 


\section{Metode Penelitian}

Penelitian ini dilaksanakan pada Gapoktan Rafi Musri milik Bapak Sumariadi di Desa Muktisari, Kecamatan Bone-Bone, Kabupaten Luwu Utara, Sulawesi Selatan pada bulan Mei sampai April 2019. Penelitin ini menggunakan metode analisis perencanaan pengembangan (APPAS) yang menitikberatkan peneliti terlibat dalam proses yang terjadi dalam usaha sehingga peneliti mampu mengetahui permasalahan secara mendalam terkait Gapoktan Rafi Musri.

\section{Hasil dan Pembahasan}

\section{a. Pemahaman Situasi Kasus}

Gapoktan Rafi Musri Bapak Sumariadi memiliki visi yaitu "Gapoktan yang mandiri, Berbasis Mutu Alsintan yang Handal dan Berdaya Saing Menuju Masyarakat yang Sejahtera". Sedangkan misi yang dilakukan untuk mencapai visi tersebut adalah Menetapkan mutu pelayanan dan pengembangan standrarisasi Alat dan Mesin Pertanian (Alsintan), dan Membangun jaringan kualitas dan kuantitas Alat dan Mesin Pertanian (Alsintan).

1. Struktur Organisasi

Struktur organisasi Gapoktan Rafi Musri Pemanfaat Program brigade alat dan mesin pertanian (BAST), diperlukan untuk menunjukkan kedudukan, tugas, dan tanggung jawab yang berbeda-beda pada setiap tenaga kerja yang terlibat dalam struktur organisasi untuk mencapai sasaran yang diiginkan struktur organisasi yang dikembangkan kiranya dapat membantu program brigade alat dan mesin pertanian (BAST) untuk mencapai tujuan yaitu dapat dilihat pada struktur organisasi tersebut.

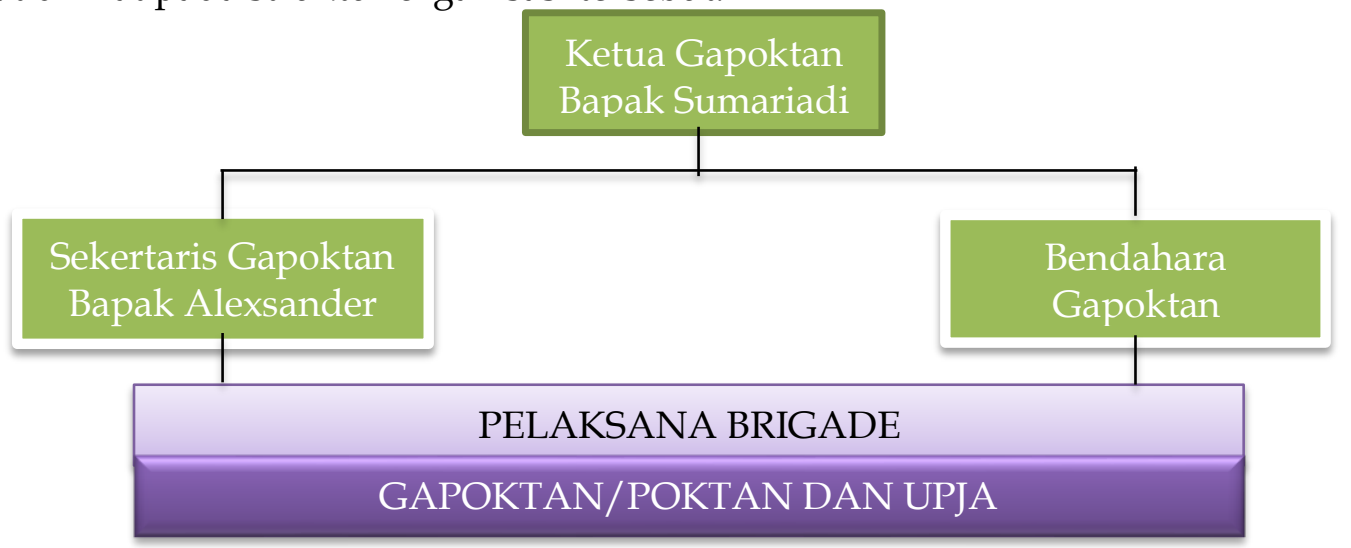

2. Analisis Posisi Sumber Daya

Gapoktan Rafi Musri Bapak Sumariadi memiliki lahan bangunan seluas $10 \mathrm{~m}^{2} \times 16 \mathrm{~m}^{2}$ dan lahan parker seluas $7 \mathrm{~m}^{2} \times 5 \mathrm{~m}^{2}$ sehingga jumlah dana yang digunakan untuk memperoleh lahan tersebut sebesar Rp 55.000.000.

Sedangkan sumber daya manusia terdiri dari 11 termasuk Bapak Iwan sebagai kepala gudang, Bapak sumariadi ketua Gapoktan dan Yudi Operator, dan 7 orang pekerja dengan upah yang diterima sebesar 30\% dari hasil penjualan gabah. Saat berjalannya oprasional teaga kerja operator tidak menjalankan pekerjaan dengan baik. Hal ini dapat membuat kinerja kurang maksimal dalam bekerja dan kurangnya kesadaran untuk serius dalam bekerja, sehingga membutuhkan waktu yang cukup lama dalam proses pemanenan. Sumber daya manusia yang terlibat dalam pemanfaatan program brigade alat dan mesin pertanian (BAST) pada Gapoktan Rafi Musri yaitu dapat diliat pada tabel 1. 
Tabel 1

Jumlah Sumber Daya Manusia yang Terlibat dalam Program Brigade Alat dan Mesin Pertanian

\begin{tabular}{cccccccc}
\hline No. & Nama & $\begin{array}{c}\text { Umur } \\
(\text { Thn })\end{array}$ & $\begin{array}{c}\text { Pendidikan } \\
\text { Terakhir }\end{array}$ & Jabatan & Status & $\begin{array}{c}\text { Lama Kerja } \\
(\text { Thn })\end{array}$ & Jam Kerja \\
\hline 1. & Irwan & 47 & SMA & Kepala Gudang & Tetap & 2 & 8 \\
2. & Sumariadi & 43 & SMA & Ketua Gapoktan & Tetap & 4 & 8 \\
3. & Yudi & 24 & SMA & Mobilisasi & Tetap & 2 & 8 \\
4 & Harianto & 25 & SMA & Operator & Tetap & 2 & 8 \\
5. & M. Rahmadza & 22 & SMA & Anggota & Tetap & 2 & 8 \\
6. & Ical & 15 & SMP & Anggota & Tidak Tetap & 1 & 8 \\
7. & Supri & 25 & SMP & Anggota & Tetap & 2 & 8 \\
8. & Dirli & 23 & SMP & Anggota & Tetap & 1 & 8 \\
9. & Shariana & 24 & SMP & Anggota & Tetap & 2 & 8 \\
10. & Risman & 40 & SMA & Anggota & Tidak Tetap & 2 & 8 \\
11. & Arifin & 50 & SMA & Anggota & Tetap & 2 & 8 \\
\hline
\end{tabular}

Sumber daya peralatan dengan jumlah 33 unit alat dan mesin pertanian dengan nilai penyusutan sebesar Rp91.699,995/tahun sehingga dalam satu tahun dikeluarkan biaya penyusutan alat sebesar Rp7.642,000/ perbulan, yaitu dapat dilihat pada tabel 2 .

Tabel 2

Jenis-Jenis Peralatan Program Brigade Alat dan Mesin Pertanian (BAST)

\begin{tabular}{|c|c|c|c|c|c|c|c|}
\hline No. & Nama Alat & $\begin{array}{c}\text { Jumlah } \\
\text { Alat } \\
\text { (Satuan) }\end{array}$ & $\begin{array}{l}\text { Harga Awal } \\
\text { (Rp) }\end{array}$ & $\begin{array}{l}\text { Harga Akhir } \\
\text { (Rp) }\end{array}$ & $\begin{array}{c}\text { Umur } \\
\text { Ekonomis } \\
\text { (Thn) }\end{array}$ & $\begin{array}{c}\text { Nilai } \\
\text { Penyusutan (Rp) }\end{array}$ & Tipe \\
\hline 1. & Traktor Roda 4 & 6 & 140.000 .000 & 60.000 .000 & 10 & 48.000 .000 & $\operatorname{Maxx} 404$ \\
\hline 2. & Hand Traktor & 6 & 36.000 .000 & 18.000 .000 & 8 & 13.500 .000 & Yanmar \\
\hline 3. & Perontok Padi & 8 & 6.000 .000 & 3.000 .000 & 6 & 4.000 .000 & Yanmar \\
\hline 4. & Corn Seler Jagung & 8 & 4.000 .000 & 2.000 .000 & 5 & 3.200 .000 & Kubota 65 \\
\hline 5. & Combine Harvester & 6 & 460.000 .000 & 230.000 .000 & 10 & 22.999 .995 & $\begin{array}{l}\text { Maxi, Gunung Biru, } \\
\text { kubota dan Granstar }\end{array}$ \\
\hline & Total & 34 & 646.000 .000 & 313.000 .000 & 39 & $91,699,995$ & \\
\hline
\end{tabular}

Program Brigade Alsintan ini sudah diterapkan pada tahun 2017 kepada para petani yang ada di Kabupaten Luwu Utara. Jumlah bantuan yang di dapat di Kabupaten Luwu Utara yaitu 187 unit Brigade Alsintan. Dari 187 unit Brigade Alsintan terdiri dari tiga jenis bantuan yaitu: a). bantuan brigade alsin pasca panen sebanyak 24 unit yang terdiri dari Combine Harvester (Mesin Panen Padi) sebanyak 18 unit, Corn CombineHarvester (Mesin Panen) sebanyak 1 unit dan Cornseller sebanyak 5 unit. b.) bantuan brigade alsin pengelolaan sebanyak 99 unit yang terdiri dari traktor roda empat sebanyak 1 unit, traktor roda dua sebanyak 64 unit, pompa air sebanyak 30 unit dan Transpalanter sebanyak 3 unit. c). serta bantuan hibah sebanyak 64 unit terdiri dari traktor roda dua dari APBN sebanyak 17 unit, traktor roda dua dari APBD II sebanyak 29 unit, cultivator sebanyak 5 unit, Power Treser sebanyak 10 unit dan RMU sebanyak 3 unit. Bantuan alat dari APBN langsung di terima pihak kabupaten baru di salurkan ke kelompok tani.

Sedangkan sumber daya finansial merupakan sumber daya yang berhubungan dengan pendanaan usaha. Aktifitas finansial menggunakan dana untuk memperoleh pendapatan dan keuntungan jangka panjang. Sumber daya finansial terdiri dari aktiva lancar dan pasiva. Aktiva lancar adalah yang mudah dijadikan uang dalam jangka waktu yang relative pendek sedangkan pasiva adalah kewajiban yang harus dibayar kepada pihak ketiga (kreditur). dapat dilihat pada tabel 3 .

Berdasarkan tabel 3 pada Gapoktan Rafi Musri bahwa pada aktiva terdiri dari aktiva lancar yaitu kas sebesar Rp35.000.000 dan tidak adanya pinjaman unag ke pihak lain, dan keuntungan yang diperoleh dari 1 tahun musim tanam padi yaitu 40.000 .000 sedangkan aktifa tetap yaitu terdiri dari lahan bangunan dan lahan parker sebesar Rp. 55.000.000 dan peralatan 
sebesar Rp313.000.00 sehingga total aktiva yaitu sebesar Rp443.000.00. Sedangkan pada pasiva terdiri dari piutang untuk membeli traktor roda 4 seharga Rp140.000.00.

Tabel 3

Neraca Keuangan pemanfaat Program Brigade Alat dan Mesin Pertanian (BAST) pada Gapoktan Rafi Musri di Desa Muktisari

\begin{tabular}{|c|c|c|c|c|}
\hline & Aktiva & Nilai (Rp) & Pasiva & Nilai (Rp) \\
\hline \multirow[t]{4}{*}{$>$} & Aktiva Lancar & & $>$ Kewajiban & \\
\hline & - Kas & 35.000 .000 & $\begin{array}{l}\text { - Hutang Alat dan Mesin (Traktor } \\
\text { roda 4) }\end{array}$ & 70.000 .00 \\
\hline & - Pinjaman & - & - Biaya operator dan bahan bakar & 6.000 .000 \\
\hline & $\begin{array}{l}\text { - Keuntungan dalam } 2 \text { priode musim } \\
\text { tanam }\end{array}$ & 40.000 .000 & & \\
\hline \multirow[t]{4}{*}{$>$} & Aktiva Tetap & & & \\
\hline & - Bangunan dan Lahan Parkir & 55.000 .000 & $>$ Modal Milik & 35.000 .00 \\
\hline & - Peralatan & 313.000 .00 & & \\
\hline & Total & 443.000 .00 & & 443.000 .000 \\
\hline
\end{tabular}

3. Analisis Kinerja Brigade Alat dan Mesin Pertanian (BAST) pada Gapoktan Rafi Musri

Mekanisme Penetapa Calon Penerima dan Calon Lokasi (CPCL)

Dalam menentukan calon penerima dan calon lokasi (CPCL) harus mengajukan permohonan (proposal/surat) pengajuan peminjaman alat dan mesin pertanian Brigade di Kabupaten harus benar-benar atas kesepakatan Poktan dan Gapoktan, dan pengajuan proposal tersebut didasarkan pada kebutuhan alat dan mesin pertanian (Alsintan) ditingkat lapangan. Dalam pengelolaan alat dan mesin pertanian (Alsintan) Brigade, pembiayaan oprasional dan perawatan alat dan mesin pertanian (Alsintan) menjadi tanggung jawab sepenuhnya Poktan dan Gapoktan selaku peminjam alat dan mesin pertanian (Alsintan) tersebut. Setelah data proposal tersebut sesuai dengan keadaan yang ada dilapangan baru akan di tetapkan sebagai calon penerima dan calon lokasi pemanfaat Brigade alat dan mesin pertanian (BAST).

$>$ Mekanisme Peminjaman Alat

Mekanisme peminjaman alat dan mesin pertanian (Alsintan) yang ada di desa Muktisari pada Gapoktan Rafi Musri yang memanfaatkan Brigade alat dan mesin pertanian (BAST) yaitu Gapoktan yang akan memanfaatkan Alat dan Mesin Pertanian untuk proses pasca panen harus mengusulkan proposal akan kebutuhan peminjaman alat yang berisikan jumlah luas lahan dan jumlah anggota kelompok tani. Dalam pembuatan proposal ini harus diketahui oleh penyuluh pertanian, dan penyuluh pertanian (PPL) akan memverifikasi proposal tersebut apakah proposal tersebut layak tidaknya untuk diberikan pinjaman alat, setelah di verifikasi usulan proposal tersebut, dan di setujui Gapoktan harus melengkapi berkas-berkas sebagai bukti penyaluran pinjam pakai alsintan seperti surat pernyataan fakta integritas dalam perawatan alat dan mesin pertanian dan kontrak peminjaman alat dan mesin pertanian, dan menanggung semua biaya yang dikeluarkan seperti jasa sopir dan mobil, biaya bahan bakar dan pegawai operator alat dan mesin pertanian.

$>$ Penyaluran Pemanfaatan Brigade Alat dan Mesin Pertanian

Penyaluran pemanfaatan program Brigade alat dan mesin pertanian (BAST) ke Gapoktan Rafi Musri di desa Muktisari, dimana proses penyalurannya dimana Gapoktan harus datang ke gudang penyimpanan dengan membawa bukti adanya pinjam pakai alat dan mesin pertanian, kemudian alat dan mesin pertanian yang dibutuhkan akan di bawah ke lokasi persawahan dengan menggunakan mobil tronton. Dimana alat yang di ditribusikan harus dalam keadaan baru dan sistem oprasional alat di tanggung oleh pengguna jasa seperti kelompok tani dan gapoktan.

$>$ Wilayah Kerja Oprasional 
Kriteria lokasi lahan adalah suatu proses penilaian sumber daya lahan untuk tujuan tertentu yang akan memberikan informasi atau arahan penggunaan lahan sesuai dengan keperluan. Lahan dapat ditentukan nilai potensi suatu lahan untuk tujuan tertentu agar dapat diketahui kondisi dan kelas kesesuain lahan sebagai sumberdaya pendukung untuk pengembangan tanaman pangan.

$>$ Pemeliharaan Alat

Dalam pengelolaan Brigade Alat dan Mesin Pertanian (BAST) pada Gapoktan pembiayaan oprasional dan perawatan alat dan mesin pertanian menjadi tanggung jawab sepenuhnya pada Gapotan Rafi Musri yang memanfaatkan pinjam pakai alat dan mesin pertanian (Alsintan).

b. Mengenal Masalah Kasus pada Yunit Gapoktan Rafi Musri Pemanfaat Program Brigade Alat dan Mesin Pertanian (BAST)

Terdapat beberapa masalah yang telah teranalisis dalam Gapoktan Rafi Musri Bapak Sumaridi. Untuk mengetahui masalah tersebut dapat dilihat pada Tabel 4 tentang kesenjangan antara fakta, masalah dan harapan pada Gapoktan Rafi Musri Pemanfaat Brigade Alat dan Mesin Pertanian (BAST) Bapak Sumariadi, dapat dilihat pada tabel 4.

Tabel 4

Matriks Kesenjangan antara, Fakta, Masalah dan Harapan pada Program Brigade Alat dan Mesin Pertanian (BAST).

\begin{tabular}{|c|c|c|c|}
\hline No. & Fakta & Masalah & Harapan \\
\hline 1. & Tingkat Kerusakan Alat $50 \%$ & $\begin{array}{c}\text { Tingkat Kerusakan Alat yang di } \\
\text { Terima Tinggi }\end{array}$ & $\begin{array}{l}\text { Tingkatan kerusakan alat menjadi } \\
10 \%\end{array}$ \\
\hline 2. & $\begin{array}{l}\text { Investasi pengadaan alat } \\
\text { rendah Rp. } 40.000 .00\end{array}$ & $\begin{array}{c}\text { Investasi Gapoktan dalam } \\
\text { Pengadaan Alat Sendiri Rendah }\end{array}$ & $\begin{array}{l}\text { Investasi pengadaan alat menjadi } \\
\text { Rp.120.000.000 }\end{array}$ \\
\hline 3. & $\begin{array}{l}\text { Tingkat penerimaan dalam } \\
\text { satu priode musim tanam } \\
\text { Rp. } 20.000 .000\end{array}$ & $\begin{array}{c}\text { Tingkat Penerimaan Gapoktan } \\
\text { dalam Memperoleh Imbal Jasa } \\
\text { Alat Rendah }\end{array}$ & $\begin{array}{l}\text { Tingkat penerimaan dalam satu } \\
\text { priode musim tanam Rp. } 80.000 .000\end{array}$ \\
\hline 4. & $\begin{array}{l}\text { Kebutuhan alat yang terpenuhi } \\
34 \text { unit }\end{array}$ & $\begin{array}{l}\text { Kebutuhan Pengguna Alsintan } \\
\text { oleh Petani belum Terpenuhi }\end{array}$ & Kebutuhan alat menjadi 43 unit \\
\hline 5. & $\begin{array}{l}\text { Mesin/Peralatan } \\
\text { - } 6 \text { Traktor roda } 4 \\
\text { - } 6 \text { Hand traktor } \\
\text { - } 8 \text { Perontok padi } \\
\text { - } 8 \text { Corn seler jagung } \\
\text { - } 5 \text { Combine Hervester }\end{array}$ & Jumlah Peralatan Kurang & $\begin{array}{l}\text { Mesin/Peralatan } \\
\text { - } 8 \text { Traktor roda } 4 \\
\text { - } 8 \text { Hand traktor } \\
\text { - } 10 \text { Perontok padi } \\
\text { - } 10 \text { Corn seler jagung } \\
\text { - } 7 \text { Combine harvester }\end{array}$ \\
\hline 6. & $\begin{array}{l}\text { Dalam satu kali pekerjaan rata- } \\
\text { rata } 2 \text { jam/Ha }\end{array}$ & $\begin{array}{c}\text { Penanganan Pengguna Jasa } \\
\text { Alsintan kepada Anggota } \\
\text { Lamban }\end{array}$ & $\begin{array}{l}\text { Dalam satu kali pekerjaan seharusnya } \\
1 \text { jam/Ha }\end{array}$ \\
\hline 7. & $\begin{array}{l}\text { Yang membiayai perawatan } \\
\text { alat operator }\end{array}$ & $\begin{array}{l}\text { Alokasi Dana untuk Perawatan } \\
\text { Alat belum ada }\end{array}$ & $\begin{array}{l}\text { Alokasi biaya untuk perawatan alat } \\
\text { tersedia }\end{array}$ \\
\hline 8. & $\begin{array}{l}\text { Masa pinjam alat selama } 1 \\
\text { musim tanam } 1 \text { bulan }\end{array}$ & Masa Pinjam Alat yang Singat & $\begin{array}{l}\text { Masa pinjam alat selama } 1 \text { musim } \\
\text { tanam menjadi } 1 \text { tahun }\end{array}$ \\
\hline 9. & $\begin{array}{l}\text { Pengajuan proposal } \\
\text { mengalami penolakan }\end{array}$ & $\begin{array}{l}\text { Persetujuan Proposal Pinjam } \\
\text { Pakai Alat belum Terealisasi }\end{array}$ & Persetujuan proposal cepat terealisasi \\
\hline 10. & $\begin{array}{l}\text { Tenaga kerja yang } \\
\text { berkoordinasi pada bast belum } \\
\text { ada }\end{array}$ & $\begin{array}{l}\text { Belum ada Upaya dalam } \\
\text { Pendekatan kepada BAST }\end{array}$ & $\begin{array}{l}\text { Adanya upaya dalam pendekatan } \\
\text { kepada BAST }\end{array}$ \\
\hline 11. & $\begin{array}{l}\text { Saat berjalannya oprasional } \\
\text { tenaga operator tidak } \\
\text { menjalankan pekerjaan dengan } \\
\text { baik }\end{array}$ & $\begin{array}{c}\text { Tenaga Operator Alat tidak } \\
\text { Fokus }\end{array}$ & $\begin{array}{l}\text { Tenaga kerja operator fokus dalam } \\
\text { bekerja }\end{array}$ \\
\hline
\end{tabular}


Berdasarkan pada tabel 4 maka dapat diketahui bahwa masalah utama dari Gapoktan Rafi Musri pemanfaat program Brigade alat dan mesin pertanian (BAST) yaitu kebutuhan pengguna alsintan oleh petani belum terpenuhi, yang disebabkan jumlah peralatan kurang dan kebutuhan petani yang ingin menggunakan pinjam pakai alat belum terpenuhi secara keseluruhan, petani membutuhkan alat tetapi alat tidak tersedia. Dengan adanya BAST agar petani dapat memanfaatan alat yang tersedia agar pekerjaan yang dilakukan lebih muda, dan adanya alat agar Gapoktan mendapatkan keuntungan agar dapat berinvestasi untuk membeli alat dan mesin pertanian sendiri dan untuk memenuhi kebutuhan petani. Dimana masalah utama yang sebagaimana telah diurakan diatas yaitu kebutuhan pengguna alsintan oleh petani belum terpenuhi muncul karena disebabkan oleh tiga masalah yaitu tingkat kerusakan alat yang diterima tinggi, jumlah peralatan kurang dan penanganan pengguna jasa alat dan mesin pertanian (Alsintan) kepada anggota lamban. Masalah utama tersebut menyebabkan masalah dampak yaitu investasi Gapoktan dalam pengadaan alat sendiri rendah dan tingkat penerimaan Gapoktan dalam imbal jasa pengguna alat rendah.

Sehingga untuk mengatasi masalah utama dibutuhkan sasaran utama yaitu kebutuhan pengguna alsintan oleh petani terpenuhi. Sasaran utama dapat tercapai apabila sasaran antara tercapai yaitu tingkat kerusakan alat rendah, jumlah peralatan bertambah penanganan pengguna jasa alsintan cepat. Dengan tercapainya sasaran utama maka akan muncul sasaran dampak yang terjadi yaituinvestasi gapoktan dalam pengadaan alat sendiri meningkat dan tingkat penerimaan gapoktan dalam memperoleh imbal jasa meningkat.

c. Desain Tindakan Pengembangan pada Yunit Gapoktan Rafi Musri Pemanfaat Program Brigade Alat dan Mesin Pertanian (BAST)

Berdasarkan masalah dan sasaran yang telah dianalisis maka terdapat beberapa tindakan terpilih yang dapat dilakukan untuk mengembangkan Gapoktan Rafi Musri Pemanfaat program Brigade Alat dan Mesin Pertanian (BAST) Bapak Sumariadi yaitu mengajukan permohonan penambahan masa pinjam peralatan selama 2 tahun, mengalokasikan biaya perawatan alat sebesar 30\%, menentukan sumber perolehan tenaga kerja dari dalam Gapoktan, memiliki hubungan baik dengan penyuluh pertanian di Dinas Pertanian Kabupaten dan menentukan pengawasan langsung kinerja operator dilapangan.

d. Matriks Perencanaan Pengembangan pada Yunit Gapoktan Rafi Musri Pemanfaat Program Brigade Alat dan Mesin Pertanian (BAST)

Matriks perencanaan adalah suatu usaha untuk mengembangkan rancangan proyek yang dapat memberikan suatu ringkasan mengenai rancangan proyek pengembangan dalam bentuk sebuah matriks. Matriks ini menguraikan alternative yang erpilih dari hasil analisa keputusan dan mengidentifikasikan masing-masing sasaran terhadap ukuran tercapainya sasaran dan spesifikasi sistem informasi untuk pengendalian manajerial serta menentukan besarnya kebutuhan biaya dan saran-sarana yang diperlukan untuk melksanakan tindakan tersebut, matriks perencanaan pengembangan dapat dilihat pada tabel 5 . 
Tabel 5

Matriks Perencanaan Gapoktan Rafi Musri Pemanfaat Program Brigade Alat dan Mesin Pertanian (BAST)

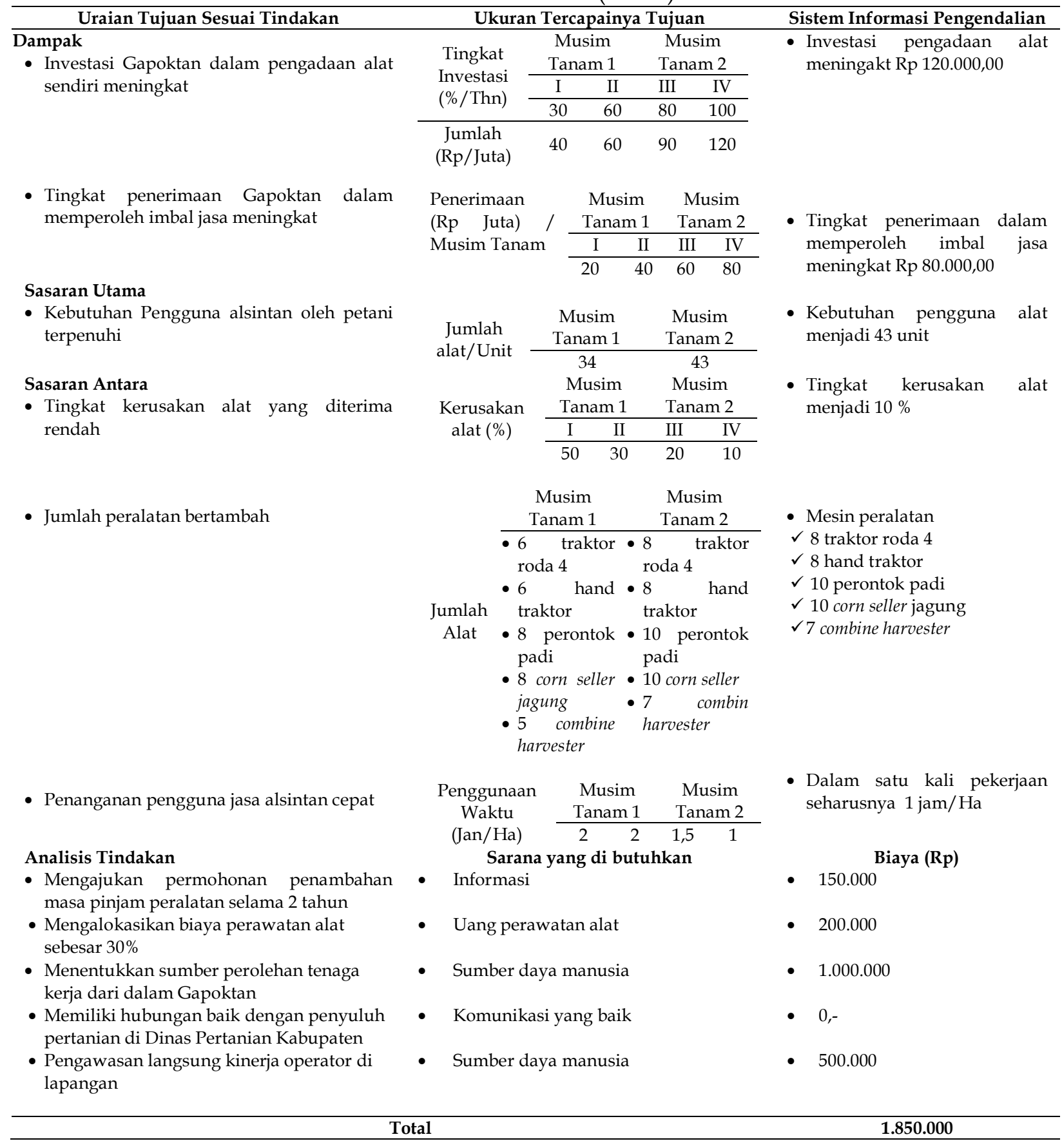

\section{e. Rencana Kerja Tindakan pada Yunit Gapoktan Rafi Musri pemanfaatan Program Brigade Alat dan Mesin Pertanian (BAST)}

Rencana kerja proyek merupakan rincian lebih lanjut dari informasi yang didapatkan dalam matriks rencana kerja proyek. Rencana kerja ini adalah suatu usaha untuk menyusun suatu kegiatan proyek yang dapat memberikan suatu ringkasan mengenai pelaksanaan rencana kegiatan agarusaha dapat berkembang dengan pesat, yang di dalamnya meliputi penanggungjawab dari masing-masing tindakan yang akan dilakukan, hasil kegiatan dan penjadwalan kegiatan. Adapun rencana kerja kegiatan dalam hal ini yang dilakukan oleh Program Brigade Alat dan Mesin Pertanian (BAST) kasus dapat dilihat pada Tabel 6. 
Tabel 6

Rencana Kerja Tindakan Gapoktan Rafi Musri Pemanfaat Program Brigade Alat dan Mesin Pertanian (BAST)

\begin{tabular}{|c|c|c|c|c|c|c|c|c|c|c|c|c|c|}
\hline \multirow{2}{*}{ Tindakan } & \multirow{2}{*}{$\begin{array}{l}\text { Penanggung } \\
\text { Jawab }\end{array}$} & \multicolumn{12}{|c|}{ Bulan } \\
\hline & & 1 & 2 & 3 & 4 & 5 & 6 & 7 & 8 & 9 & 10 & 11 & 12 \\
\hline $\begin{array}{l}\text { Mengajukan permohonan } \\
\text { penambahan masa pinjam peralatan } \\
\text { selama } 2 \text { tahun }\end{array}$ & Ketua Gapoktan & & & & & & & & & & & & \\
\hline $\begin{array}{l}\text { Mengalokasikan biaya perawatan } \\
\text { alat sebesar } 30 \%\end{array}$ & Ketua gapoktan & & & & & & & & & & & & \\
\hline $\begin{array}{l}\text { Menentukkan sumber perolehaan } \\
\text { tenaga kerja dari dalam Gapoktan }\end{array}$ & Kepala Gudang & & & & & & & & & & & & \\
\hline $\begin{array}{l}\text { Memiliki hubungan baik dengan } \\
\text { penyuluh pertanian di Dinas } \\
\text { Pertanian Kabupaten }\end{array}$ & Ketua Gapoktan & & & & & & & & & & & & \\
\hline $\begin{array}{l}\text { Pengawasan langsung kinerja } \\
\text { operator di lapangan }\end{array}$ & Kepala Gudang & & & & & & & & & & & & \\
\hline
\end{tabular}

f. Analisis Persoalan Potensial pada Yunit Gapoktan Rafi Musri Pemanfaat Program Brigade Alat dan Mesin Pertanian (BAST)

Analisis persoalan potensial adalah suatu prosedur yang memungkinkan kita untuk memasuki masa depan, melihat apa yang terkandung didalamnya untuk kemudian kembali kemasa kini untuk mengambil tindakan selagi masih memungkinkan. Analisis potensial ini memberikan solusi terhadap persoalan yang timbul. Dalam analisis persoalan potensial ada beberapa langkah yang harus ditempuh yaitu merumuskan pernyataan rencana kegiatan, menyusun sekenario pelaksanaan kegiatan, menyusun sekenario pelaksanaan kegiatan, mengidentifikasi persoalan potensial khusus dan menentapkan tindakan-tindakan pencegahan serta tindakan penanggulangan. Dalam analisis persoalan potensial dibedakan menjadi 6 bagian yaitu perencanaan kegiatan, scenario pelaksanaan kegiatan, identifikasi tahap-tahap rawan, identifikasi persoalan potensial khusus, identifikasi sebab-sebab persoalan potensial khusus, tindakan pencegahan dan tindakan penanggulangan. Adapun analisis persoalatn potensial hal ini yang dilakukan oleh Program Brigade Alat dan Mesin Pertanian (BAST) kasus dapat dilihat pada Tabel 7. 
Tabel 7

Matriks Analisis Persoalan Potensial pada Program Brigade Alat dan Mesin Pertanian (BAST)

\begin{tabular}{|c|c|c|c|c|c|c|}
\hline \multirow{2}{*}{$\begin{array}{l}\text { Pernyataan } \\
\text { Keputusan }\end{array}$} & \multirow{2}{*}{$\begin{array}{l}\text { Skenario Pelaksanaan } \\
\text { Kegiatan }\end{array}$} & \multirow{2}{*}{$\begin{array}{l}\text { Identifikasi Tahap- } \\
\text { Tahap Rawan }\end{array}$} & \multirow{2}{*}{$\begin{array}{l}\text { Identiffikasi Persoalan } \\
\text { Potensial Khusus }\end{array}$} & \multirow{2}{*}{$\begin{array}{c}\text { Identifikasi } \\
\text { SebabSebab } \\
\text { Persoalan Potensia }\end{array}$} & \multicolumn{2}{|c|}{ Tindakan } \\
\hline & & & & & Pencegahan & Penanggulangan \\
\hline $\begin{array}{c}\text { Mengajukan } \\
\text { Permohonan } \\
\text { Penambahan Masa }\end{array}$ & $\begin{array}{l}\text { - Menyususn } \\
\text { Permohonan }\end{array}$ & $\begin{array}{l}\text { - Model bentuk } \\
\text { permohonan }\end{array}$ & $\begin{array}{l}\text { - Belum mengetahui } \\
\text { bentuk permohonan } \\
\text { penambahan masa pinjam } \\
\text { alat }\end{array}$ & $\begin{array}{l}\text { - Belum pernah } \\
\text { mengajukan } \\
\text { permohonan }\end{array}$ & $\begin{array}{l}\text { - Berkoordinasi dengan } \\
\text { penyuluh pertanian lapangan }\end{array}$ & $\begin{array}{l}\text { - Membuat permohonan } \\
\text { lisan }\end{array}$ \\
\hline $\begin{array}{l}\text { Pinjam Peralatan } \\
\text { selama } 2 \text { tahun }\end{array}$ & $\begin{array}{l}\text { - Menyampaikan } \\
\text { Permohonan }\end{array}$ & $\begin{array}{l}\text { - Penyususnan model } \\
\text { permohonan }\end{array}$ & $\begin{array}{l}\text { - Tidak ada anggota yang } \\
\text { bisa menyusun } \\
\text { permohonan }\end{array}$ & $\begin{array}{l}\text { - Angggota belum } \\
\text { pernah membuat } \\
\text { permohonan }\end{array}$ & $\begin{array}{l}\text { - Berkoordinasi dengan } \\
\text { penuluh pertanian lapangan } \\
\text { daerah setempat }\end{array}$ & $\begin{array}{l}\text { - Menyampaikan } \\
\text { permohonan secara lisan }\end{array}$ \\
\hline $\begin{array}{l}\text { Mengalokasikan Biaya } \\
\text { Perawatan Alat } \\
\text { sebesar } 30 \%\end{array}$ & - Menyediakan dana & $\begin{array}{l}\text { - Ketersedian jumlah } \\
\text { dana }\end{array}$ & $\begin{array}{l}\text { - Jumlah dana yang } \\
\text { dibutuhkan tidak } \\
\text { mencukupi }\end{array}$ & $\begin{array}{l}\text { - Pengeluaran alat } \\
\text { terlalu besar }\end{array}$ & - Menyediakan dana khusus & $\begin{array}{l}\text { - Menggunakan dana } \\
\text { Gapoktan }\end{array}$ \\
\hline $\begin{array}{l}\text { Menentukan Sumber } \\
\text { Perolehan Tenaga }\end{array}$ & $\begin{array}{l}\text { - Menentukan } 3 \\
\text { orang yang dapat } \\
\text { dijadikan tenaga } \\
\text { kerja }\end{array}$ & $\begin{array}{l}\text { - Kesesuaian tenaga } \\
\text { kerja dengan petani }\end{array}$ & $\begin{array}{l}\text { - Sulitnya menyesuaikan } \\
\text { keinginan petani }\end{array}$ & $\begin{array}{l}\text { - Kurangnya tenaga } \\
\text { kerja }\end{array}$ & $\begin{array}{l}\text { - Mencari tenaga kerja yang } \\
\text { sejalan dengan keinginan petani }\end{array}$ & $\begin{array}{l}\text { Menentukan tenaga kerja } \\
\text { yang tidak membebani } \\
\text { petani }\end{array}$ \\
\hline $\begin{array}{l}\text { Kerja dari Dalam } \\
\text { Gapoktan }\end{array}$ & $\begin{array}{l}\text { - Menentukan tenaga } \\
\text { kerja yang memiliki } \\
\text { potensi }\end{array}$ & - Keahlian tenaga kerja & $\begin{array}{l}\text { - Keahlian tenaga kerja } \\
\text { tidak baik }\end{array}$ & $\begin{array}{l}\text { - Kurangya } \\
\text { pengetahuan yang } \\
\text { dimiliki oleh } \\
\text { pekerja }\end{array}$ & $\begin{array}{l}\text { - Memberikan pengetahuan yang } \\
\text { dimiliki oleh pekerja }\end{array}$ & $\begin{array}{l}\text { - Memberian pelatihan } \\
\text { yang baik kepada pekerja }\end{array}$ \\
\hline $\begin{array}{l}\text { Memiliki Hubungan } \\
\text { Baik dengan Penyuluh }\end{array}$ & $\begin{array}{l}\text { - Menjalin } \\
\text { komunikasi dengan } \\
\text { penyuluh pertanin } \\
\text { lapangan }\end{array}$ & $\begin{array}{l}\text { Kurangya petani } \\
\text { dalam } \\
\text { berkomunikasi }\end{array}$ & $\begin{array}{l}\text { - Petani tidak } \\
\text { berkomunikasi }\end{array}$ & $\begin{array}{l}\text { - Petani takut } \\
\text { berkomunikasi } \\
\text { dengan baik }\end{array}$ & $\begin{array}{l}\text { - Petani melakukan komunikasi } \\
\text { dengan pihak laini }\end{array}$ & $\begin{array}{l}\text { - Petani melakukan } \\
\text { komuniksi dengan } \\
\text { penyuluh pertanian } \\
\text { dengan baik }\end{array}$ \\
\hline $\begin{array}{l}\text { Pertanian di Dinas } \\
\text { Pertanian Kabupaten }\end{array}$ & $\begin{array}{l}\text { - Menyampaikan } \\
\text { komunikasi dengan } \\
\text { baik }\end{array}$ & - Penyuluh pertanian & $\begin{array}{l}\text { - Penyuluh pertanian tidak } \\
\text { mau bekerja sama }\end{array}$ & $\begin{array}{l}\text { - Petani sudah } \\
\text { bekerjasama dengak } \\
\text { pihak lain }\end{array}$ & $\begin{array}{l}\text { Melakukan komunikasi ulang } \\
\text { dengan penyuluh pertanian } \\
\text { yang bersangkutan di } \\
\text { lapangan }\end{array}$ & $\begin{array}{l}\text { - Melakukan komunikasi } \\
\text { ulang dengan penyuluh } \\
\text { pertanian lain di lapangan }\end{array}$ \\
\hline $\begin{array}{l}\text { Pengawasan } \\
\text { Langsung Kinerja } \\
\text { Operator di La } \\
\text { pangan }\end{array}$ & $\begin{array}{l}\text { - Memberikan } \\
\text { pengawasan khusus } \\
\text { kepada tenaga kerja }\end{array}$ & $\begin{array}{l}\text { - Adanya tenaga } \\
\text { kerja yang bekerja } \\
\text { tidak optimal }\end{array}$ & $\begin{array}{l}\text { - Sulit mencari pekerja } \\
\text { yang benar-benar } \\
\text { memiliki kwalitas dan } \\
\text { kinerja yang baik }\end{array}$ & $\begin{array}{l}\text { - Kurangya pekerja } \\
\text { yang } \\
\text { berpengalaman }\end{array}$ & $\begin{array}{l}\text { - Mengadakan pelatihan kerja } \\
\text { secara langsung }\end{array}$ & $\begin{array}{l}\text { - Mendatangkan ahli yang } \\
\text { siap membantu para } \\
\text { pekerja apabila pekerja } \\
\text { mengalami kesulitan } \\
\text { dalam pengawasan } \\
\text { langsung di lapangan }\end{array}$ \\
\hline
\end{tabular}




\section{Kesimpulan}

Masalah yang dimiliki oleh Gapoktan Rafi Musri Bapak Sumariadi yaitu kebutuhan pengguna alsintan oleh petani belum terpenuhi, tingkat kerusakan alat yang diterima tinggi, jumlah peralatan kurang, penaganan pengguna jasa alsintan kepada anggota lamban, alokasi dana perawatan belum ada, masa pinjam alat yang singkat, persetujuan proposal pinjam pakai alat belum terealisasai, belum ada upaya dalam pendekatan pada BAST, tenaga operatol alat tidak fokus, investasi Gapoktan dalam pengadaan alat sendiri rendah, dan tingkat penenrimaan Gapoktan dalam memperoleh imbal jasa pengguna alat rendah. Sehingga untuk mengembangkan Gapoktan Rafi Musri yaitu kebutuhan pengguna alsintan oleh petani terpenuhimaka perlu dilakukan beberapa tindakan pengembangan yaitu mengajukan permohonan penambahan masa pinjam peralatan selama 2 tahun, menglokasikan biaya perawatan sebesar 30\%, menentukan sumber perolehan tenaga kerja dari dalam Gapoktan, memiliki hubungan baik dengan penyuluh pertanian di Dinas Pertanian Kabupaten dan menentukan pengawasan langsung kinerja operator di lapangan.

\section{Daftar Pustaka}

Aditya. 2010. Visi dan Misi Perusahaan. Di Akses Melalui www.pdf.database.com

Amran. 2011. Analisis Alternatif Tindakan Pengembangan Agrosistem. http:// repository.uny.ac.id. Diakses pada tanggal 10 April 2019 Makassar.

Aswar. 2010. Analisis Perancangan Pengembangan Agrosistem (Appas). Fakultas Pertanian Masyarakat Universitas Airlangga. Surabaya.

Badan Pusat Statistik Kabupaten Luwu Utara, 2017. Kabupaten Luwu Utara Dalam Angka 2016. Luwu Utara: Badan Pusat Statistik. Diakses pada hari Jumat 09 April 2019.

Djoko. 2010. Koperasi, Kewirausahaan, dan Usaha Kecil. Jakarta. PT. Rineka Cipta.

Hartadi, Ari Muhammad. 2016. Analisis Kinerja Pelayanan Jasa Alat Mesin Pertanian (UPJA) di Kabupaten Nnunukan. Skripsi Progran Pasca Sarjana Universitas Terbuka Jakarta. Jakarta.

Haryono Yususf. 2013. Dasar-Dasar Akutansi, Jilid 2 Cetakan Pertama Desember 2013. Sekolah Tinggi Ekonomi Yayasan Keluarga Pahlawan Negara. Yogyakarta.

Ikma. 2013. Pohon Masalah. Fakultas Pertanian Masyarakat Universitas Airlangga. Surabaya.

Kasmir, S, E.,MM. dan Jakfar, S,E.,MM. 2010. Studi Kelayakan Bisnis Edisi ke 2. Kencana. Jakarta.

Kementrian Pertanian. 2017. Pedoman Umum Pengelolaan Brigade Alsintan. Kementrian Pertanian.

Kementrian Pertanian. 2018. Pedoman Umum Pengelolaan Brigade Alsintan. Kementrian Pertanian.

Morri, M.J. 2009. Kiat Sukses Pengembangan Usaha Kecil. Arcan. Jakarta.

Pambudy. 2011. Pengertian Sumber Daya Peralatan. Di Akses Melalui www.id.shyoong.com

Pranoto, Hardi, Subagiyo, Bambang, Said. 2009. Metode Efektif Pemecahan Masalah dan Pengambilan Keputusan. PPM. Jakarta.

Rivai, Veithzal. 2006. Manajemen Sumber Daya Manusia untuk Perusahaan. PT. Raja Grafindo Persada. Jakarta.

Salim, Agus. 2012. Analisis Perancangan dan Pengembangan Agrosistem. http://ojs.unud.ac.id. Diakses pada tanggal 15 April 2019. Makassar. 
Sugtandi. 2009. Rencana Kerja Proyek. http://joernal.widyatama.ac.id. Diakses pada tanggal 15 April 2019. Makassar.

Suryana, 2010. Kewirausahaan. Jakarta. Salemba Empat.

Togatorop, Boyma, 2017. Hubungan Teknologi Alsintan Terhadap Produktivitas Padi Sawah Di Desa Sri Agung Kecamatan Batang Asam Kabupaten Tanjung Jabung Barat. Skripsi. Jurusan/ Program Studi Agribisnis Fakultas Pertanian Universitas Jambi. Jambi.

Wandani Sari, Dwi.2018. Upaya Pemanfaatan Pekarangan Melalui Vertikultur Di Desa Di Desa Tompotana Kecamatan Mappakasunggu. Kepulauan Tanakeke Kabupaten Takalar. 